\title{
A VISIBILIDADE INSTITUCIONAL DO IF GOIANO - CAMPUS URUTAÍ
}

\author{
João Oliveira Ramos Neto; Érica Aparecida Vaz Rocha; Thayná Baida Garcia Coutinho \\ Instituto Federal Goiano \\ DOI: $10.15628 /$ rbept.2019.8355
}

Artigo submetido em fev/2019 e aceito em abr/2019

\section{RESUMO}

O objetivo deste artigo é analisar a visibilidade do Instituto Federal Goiano - Campus Urutaí pela comunidade onde ele está. Este artigo é resultado de uma pesquisa de iniciação científica (PIBIC). Na primeira parte, apresentamos a conceituação teórica sobre visibilidade institucional. Na segunda parte, apresentamos as estratégias usadas pelo campus Urutaí para divulgar seus cursos. Na terceira parte, apresentamos o resultado da pesquisa feita para verificação dessa estratégia. Por fim, concluímos com sugestões para melhorar a visibilidade e a eficácia da divulgação dos cursos para os processos seletivos.

Palavras-Chave: Visibilidade. Reputação. IF Goiano. Ensino Técnico profissionalizante. Ensino Médio.

\section{THE INSTITUCIONAL VISIBILITU OF IF GOIANO - CAMPUS URUTAÍ}

\begin{abstract}
The objective of this article is to analyze the visibility of the Instituto Federal Goiano - Campus Urutaí by the community where it is. This article is a research initiation program (PIBIC). In the first part, we present a theoretical conceptualization about institutional visibility. In the second part, we present the strategies used by the campus to promote their courses. In the third part, we present the result of the research for the adjustment of this strategy. Finally, concludes with suggestions to improve the visibility and dissemination of the courses for the selective processes.
\end{abstract}

Keywords: Visibility. Reputation. IF Goiano. Technical Education. High School.

\section{INTRODUÇÃO}

Este artigo é resultado de uma pesquisa de iniciação científica que teve como ponto de partida a seguinte questão: como o ensino técnico oferecido pelo campus Urutaí do Instituto Federal Goiano é visto pela comunidade onde ele está inserido? As atuais estratégias de divulgação utilizadas estão sendo eficazes? A pesquisa feita comprova ou não a respectiva teoria? Estas perguntas nortearam esta pesquisa sobre a visibilidade institucional da instituição em questão. 
O campus Urutaí é um campus do Instituto Federal de Educação, Ciência e Tecnologia Goiano, situado no município de Urutaí, no estado de Goiás. Nele, atualmente, são oferecidos três cursos técnicos integrados ao Ensino Médio: Técnico em Agropecuária, Técnico em Informática e Técnico em Biotecnologia. Daqui em diante nos reportaremos a ele pela forma abreviada, Instituto Federal Goiano - Campus Urutaí ou, simplesmente, IF.

Sua localização geográfica está na região sudeste do estado de Goiás, conhecida também como "região da estrada de ferro", cuja população, somados os municípios, não ultrapassa 50 mil habitantes. Dessa forma, além de Urutaí, ele atinge municípios, entre outros, como Pires do Rio (que fica a apenas 20 quilômetros de Urutaí), Orizona e Palmelo, de onde vem a maioria de seus alunos. Por ser a maior cidade da região, e tradicionalmente ser a origem da maioria dos alunos, esta pesquisa partiu principalmente da cidade de Pires do Rio, mas sem desprezar Palmelo e Orizona. Em outras palavras, nossa pesquisa objetivou compreender como se dá o processo de construção da visibilidade dos cursos técnicos do Instituto Federal de Educação, Ciência e Tecnologia Goiano, campus Urutaí, na cidade de Pires do Rio e região.

Num primeiro momento, fizemos um levantamento bibliográfico e, entre o material encontrado, destacou-se a dissertação de Daiane Scheid sobre a visibilidade institucional da Universidade Federal de Santa Maria. Diante da proximidade temática, decidimos partir desse trabalho, tanto como ponto de partida, como uma espécie de suporte teórico para trabalhar com o material levantado pelo campus Urutaí do Instituto Federal Goiano.

Num segundo momento, tendo a supracitada dissertação como base, fizemos um levantamento das ações de promoção institucional realizadas pelo IF Goiano - Campus Urutaí. Após isso, fizemos uma pesquisa na comunidade para diagnosticarmos como essa percebe a referida instituição. Por fim, concluímos com o resultado acompanhado de encaminhamentos para aumentar a eficácia da promoção institucional e melhoria da sua visibilidade. Concluído o processo, espera-se que a publicação desta pesquisa possa ser relevante para outros campi que ofertam o ensino técnico preocupados com a mesma temática.

\section{CONCEITUAÇÃO E TEORIA}

A visibilidade institucional refere-se, entre outros, ao conjunto dos processos de emissão e recepção de suas mídias. Esses processos são alterados de acordo com as demandas de cada época. Atualmente, portanto, esse processo precisa ser investigado, entre outros aspectos, sob o contexto das novas formas de interação social possibilitadas pela internet.

Daiane Scheid, ao realizar sua pesquisa sobre a visibilidade institucional da Universidade Federal de Santa Maria, utilizou a categoria visível, proposta pelo filósofo Michel Foucault, pois entendeu ser uma ferramenta pertinente para entender o processo de construção da visibilidade, ou seja, "as estratégias (...) que possibilitam a iluminação de determinados fatos em detrimento de outros" (Scheid, 2008, p. 16). A essa categoria, ela 
somou a proposta da pesquisadora Fernanda Bruno, para a qual, na atualidade, "o olhar do outro deixa de ser dado pelo coletivo (a sociedade em geral) e passa a ser buscado pelo indivíduo" (Scheid, 2008, p. 16). Diante disso, é importante, portanto, perceber se, nesse processo, o IF Goiano Campus Urutaí (e, consequentemente, cada campus de um IF), tem diversificado a sua estratégia (isto é, a forma de aplicar recursos para atingir determinados objetivos) tendo como foco principal o indivíduo.

Primeiramente, quem é esse indivíduo que o IF Goiano busca alcançar? Por se tratar de cursos técnicos, seu público principal são os alunos egressos dos cursos de ensino fundamental de Pires do Rio. Por outro lado, uma reportagem do jornal Folha de São Paulo veiculou que, por serem adolescentes (um estudante conclui o ensino fundamental por volta dos 14 anos), é importante ressaltar que a palavra final de onde esse aluno estudará será dos pais. Dessa forma, é importante saber como um campus que oferece ensino técnico de nível médio (nesse caso, o IF Goiano - Campus Urutaí), investe recursos no objetivo de que a sua visibilidade institucional convença os alunos egressos do ensino fundamental e seus respectivos pais a se inscreverem no processo seletivo para cursar um dos três cursos técnicos atualmente oferecidos.

$\mathrm{Na}$ cidade de Pires do Rio há diversas formas de se promover uma marca ou instituição. As mídias mais comuns utilizadas são: outdoor, rádio, carro de som e internet. Não é possível veicular propagandas na TV já que a cidade e a região não dispõem de canais próprios. Os moradores recebem sinais de canais de outras cidades, como Goiânia, Brasília e Catalão. Além disso, a propaganda pela televisão está entre as mais caras. É claro, porém, que mesmo com tantas opções, essa diversidade não é tão abrangente como nas regiões metropolitanas de grandes centros urbanos.

Sem incorrer em um reducionismo, podemos afirmar que a mídia é compreendida, entre outros, como um fluxo comunicacional acoplado a um dispositivo, que funciona com uma lógica específica. Dessa forma, ela se constitui em uma importante estratégia institucional de eficaz construção de espaços de interação midiáticos para a percepção, pelos indivíduos, de uma imagem institucional positiva, que irá, consequentemente, gerar resultados satisfatórios para quem a emprega.

Em cada época da História, "a visibilidade adquire uma forma particular, e nosso entendimento é que, na contemporaneidade, a mídia é o principal local de disputa por visibilidade, tanto por parte de sujeitos individuais como de coletivos" (Scheid, 2008, p. 21). Então, acompanhamos a referida autora que "a visibilidade das instituições e organizações, aqui denominada visibilidade institucional, está atrelada à visibilidade midiática" (Scheid, 2008, p. 21). Portanto, a forma como a imagem do Instituto Federal Goiano - campus Urutaí, é divulgada pela mídia, afetará a sua visibilidade na comunidade onde está inserida.

Dessa forma, as constantes imagens veiculadas pelas redes sociais de alunos e ex-alunos, servidores e páginas oficiais ao longo de um período, terá um impacto maior do que uma campanha em rádios, carros de som e outdoors em um determinado período específico de inscrição em processo 
seletivo. É por isso, também, que é primordial o papel das relações públicas em uma instituição. O profissional de relações públicas visa, entre outros objetivos, legitimar as ações organizacionais. Nesse caso, é importante que, em casa campus de uma instituição, verifique-se a imagem projetada por estes meios.

Resumindo esta parte, uma introdutória pesquisa teórica constata que, na atualidade, uma comunicação institucional que visa divulgar uma instituição de ensino médio será mais eficaz se ela for voltada para o adolescente egresso do ensino fundamental, em uma perspectiva individual, priorizando o uso de redes sociais da internet e feita continuamente ao longo do ano. Nesse sentido, outras mídias devem ser acrescidas, mas, ao invés de ponto de partida fundamental, serem vistas como auxílio ou enriquecimento do processo.

Então, de posse dessas informações, constata-se que uma estratégia de construção de visibilidade que busque atrair alunos precisa atingir adolescentes individualmente. Será que essas estratégias atualmente utilizadas no campus Urutaí, então, estão atingindo-os? Ou, será que a pesquisa feita confirma a perspectiva teórica?

\section{METODOLOGIA}

Não é novidade que muitos campi de institutos federais de educação, ciência e tecnologia passem momentos de crise, quando o número de matrículas de alunos é aquém do esperado. Isso acontece, entre outros motivos, pelo volume de vagas oferecidas por diferentes instituições, que concorrem entre si, mal distribuídas pelo poder público. O campus Urutaí ainda não passa por tal problema, e esta pesquisa de Pibic visou antecipar estratégias por meio de análises justamente para evitar que chegue a se desenvolver tal situação.

Na região do sudeste goiano, que analisamos neste, por exemplo, há três campi do Instituto Federal Goiano em três cidades muito próximas: Urutaí, Ipameri e Catalão. Esses três campi concorrem com escolas particulares, conveniadas e estaduais, tendo em si a desvantagem de oferecer um curso pouco atrativo para o jovem que deseja ingressar no ensino superior. Já que o jovem que aspira a uma carreira universitária encontrará ao final do Ensino Médio um processo seletivo baseado no ENEM, este jovem muitas vezes prefere focar seus estudos em escolas concentradas nas disciplinas específicas do Ensino Médio a ter que dividir o preparo com uma formação profissionalizante. Colégios militares, cada vez mais difundidos pelo governo do estado de Goiás, acabam gerando mais atrativos para esse perfil de aluno. E, ainda que exista o interesse em formação técnica e profissionalizante, os institutos federais de educação, ciência e tecnologia acabam tendo que concorrer também com as escolas técnicas estaduais e as escolas do sistema S. 
Em 2017, como em todos os anos, uma comissão especialmente designada para isso, se encarregou de fazer o processo seletivo do IF Goiano - Campus Urutaí. Esta comissão realizou um amplo trabalho de divulgação. Para tanto, foram confeccionados 7.500 panfletos, 550 cartazes, 20 faixas, 12 banners e 100 adesivos de carros a serem distribuídos. É preciso, porém, deixar claro que essa divulgação não levou em conta exclusivamente os cursos técnicos, mas todos os cursos ofertados pela instituição. O material gráfico utilizado para o ensino técnico de nível médio foi solicitado para a reitoria, na capital, que utilizou a mesma arte para todos os campi do IF Goiano, alterando apenas os dados dos cursos, número de vagas e datas.

Com o material gráfico em mãos, a comissão montou um itinerário de visitas às escolas que oferecem ensino fundamental da região para divulgação do processo seletivo. A comissão é composta por integrantes de diferentes setores da instituição, tais como: Gerência de Ensino Técnico integrado ao Médio, Secretaria do Ensino Médio, Gerência de Assistência ao Aluno, Técnico em Informática e Assessoria de Comunicação - ASCOM. O objetivo da diversidade dos membros da comissão é, entre outros motivos, porque cada um é apto a responder eventuais dúvidas sobre seus departamentos que surjam dos alunos das escolas visitadas durante a divulgação.

Com o itinerário em mãos, as visitas são agendadas de acordo com o horário disponibilizado pela escola requisitada. A equipe entra nas salas de aula acompanhada por um representante da escola. Quando permitido é exibido o vídeo institucional com informações sobre os cursos, estrutura do campus e benefícios aos alunos. São distribuídos panfletos do processo seletivo e dos programas oferecidos pela Assistência Estudantil, como bolsas e auxílios. Na oportunidade, são fixados cartazes em um local de destaque no pátio da escola, e também em locais específicos na cidade.

No período de 2 de outubro a 24 de novembro de 2017 aconteceram visitas às escolas em Urutaí, Pires do Rio e mais 23 cidades da região. É importante salientar que as escolas localizadas nas zonas rurais nos municípios de Orizona e Silvânia também foram visitadas. Nelas, as visitas também aconteceram com o acompanhamento de um representante da Secretaria Municipal de Educação.

No mesmo período, aconteceram propagandas em cinco rádios das cidades da região, principalmente localizadas na cidade de Pires do Rio e, além das propagandas, foram agendadas nessas rádios, através da assessoria de comunicação do campus, entrevistas com professores, coordenadores de curso e com o diretor geral.

Também foi feita uma divulgação por meio de seis placas de outdoor por um período de 42 semanas, sendo um outdoor em cada cidade: Orizona, Silvânia, Pires do Rio, Flores de Goiás, Campo Alegre e Cristianópolis. E, também, foi utilizada propaganda volante por meio de carro de som. $O$ 
contrato estabelecido foi de dez horas de anúncio nas cidades de Urutaí, Orizona, Silvânia, Palmelo, Vianópolis e Santa Cruz. Foi utilizada ainda a propaganda indoor nas cidades de Pires do Rio e Ipameri.

A comissão de divulgação também participou de dois eventos realizados na instituição e um evento realizado na cidade de Ipameri, com a apresentação do vídeo institucional, entrega de panfletos e apoio para inscrições para participantes desses eventos que eram de escolas de Ensino Fundamental que estavam visitando o campus. E, durante todo o período, o campus contou com um trabalho específico da assessoria de imprensa, que fez a divulgação por meio do sítio eletrônico, e da página oficial da instituição na rede social Facebook.

Se levarmos em consideração as peculiaridades da região, principalmente $o$ aspecto da pequena densidade populacional, e contrastarmos com as possibilidades de interação propiciadas pela internet, podemos arriscar que a divulgação individual e extraoficial exerce influência maior que as mídias coletivas que visam atingir um grande público. Scheid afirma que "a Internet possibilidade uma modalidade peculiar de visibilidade institucional (...) que pode ser realizada tanto por ela como por indivíduos que dela não fazem parte" (Scheid, 2008, p. 17). Em outras palavras, os comentários veiculados nas redes sociais e na interação dos indivíduos entre si terá mais impacto que aqueles veiculados em rádios e outdoors.

Comecemos pela análise teórica da divulgação através do outdoor. Se considerarmos que o outdoor, na comunicação, é "um veículo eminentemente urbano que dirige uma mensagem à população das cidades, chamando atenção pelo seu formato e ilustração" (Maia at all, 2016, p. 2), é possível que sua eficácia na área rural seja menor. E, se considerarmos que a visibilidade institucional constituir-se-á do resultado de um processo que envolve a disponibilidade dos fatos pelos indivíduos, que o recodificam enquanto compartilha, o outdoor será pouco eficaz, já que ele "é um dos meios que mais exibe o produto e que menos explica" (Maia at all, 2016, p. 3).

Se considerarmos a relevância de um campus de um Instituto Federal de Educação, Ciência e Tecnologia em uma região com população e área relativamente pequenas, constataremos que não é necessário divulgar tanto a sua existência, como faz o outdoor, pois presumir-se-á que a população já o conhece. É preciso divulgar, porém, a sua atualidade. Nesse sentido, a população local estará mais atenta em saber como estão sendo ofertados os cursos do que saber da existência. Portanto, como já afirmamos, a divulgação individual pelas redes sociais ao longo de um ano será mais relevante do que a divulgação pontual por meio de outdoor no período do processo seletivo.

Considerando, portanto, o supracitado contexto, se, ao longo de um ano, a visibilidade institucional estiver positiva na mente das pessoas de uma dada comunidade, os candidatos irão automaticamente procurar a instituição, 
sem a necessidade de uma campanha pontual. Se, porém, não houver tal procura, é preciso lembrar ainda que outros fatores macros envolvidos, que não estão ligados à imagem institucional, mas à questões da educação em si, como o excesso de ofertas de vagas em outras instituições, entre diversos outros motivos.

Além do outdoor, o campus Urutaí do IF Goiano faz uma divulgação por meio das rádios locais. Se lembrarmos de que o seu público-alvo é constituído majoritariamente de adolescentes entre 15 e 17 anos (que tinham entre 13 e 14 quando decidiram ingressar em um dos cursos do IF Goiano campus Urutaí) é preciso questionar se essa ferramenta está alcançando esses jovens.

$\mathrm{Na}$ atual revolução digital, os jovens e adolescentes dispõem de diversos aparelhos que reproduzem música digital. Isso, inclusive, decorre da facilidade do adolescente se adaptar às novidades eletrônicas. Tanto é que, em conselhos de classe, repete-se a reclamação dos professores quanto ao uso de celulares e fones de ouvido durante suas aulas. Além de acessar música, os adolescentes também estão conectados às notícias. Estudos demonstram, portanto, que os adolescentes, atualmente, acessam as duas principais funções do rádio (música e informação) preferencialmente pela internet. Cardoso concluiu, em sua pesquisa, que os jovens ouvem, atualmente, menos de 1 hora de rádio por dia, sendo que 35,8\% deles 0 fazem nos carros e o restante em circunstâncias que tornaram o rádio um veículo de comunicação para pessoas que estão em movimento .

Sendo assim, através de uma análise teórica, constata-se que a divulgação do processo seletivo feita pelas redes sociais terá mais impacto em atingir o público-alvo formado predominantemente de adolescentes. $O$ impacto das redes sociais, pelo viés teórico, será maior que o impacto da divulgação por meio de mídia de visibilidade rápida, como o outdoor, e por rádio. Por outro lado, isso não significa que o outdoor deva ser dispensado. Ele é útil para manter a memória da instituição enquanto o público-alvo escolhe e decide a escola. Ele, porém, será ineficaz se atuar sozinho. E, eventualmente, numa situação de poucos recursos financeiros para a divulgação do processo seletivo, ele poderia entrar na lista de cortes sem maiores prejuízos. O mesmo ocorrendo com o rádio.

\section{RESULTADOS E DISCUSSÕES}

Em 2017, enquanto a comissão realizava o trabalho do processo seletivo, o que incluía aí a sua divulgação, fizemos uma pesquisa sobre a visibilidade da instituição junto a alunos de escolas da região. Quando houve a visita da comissão, o questionário era aplicado na escola após a divulgação institucional. A cidade de Pires do Rio conta com duas escolas que oferecem 
exclusivamente Ensino Fundamental, sendo uma particular e uma pública; duas escolas públicas que oferecem exclusivamente o Ensino Médio e três escolas que oferecem tanto o Ensino Médio quanto o Ensino Fundamental, sendo duas delas particulares e uma pública. Nem todas as escolas permitiram a nossa visita para a pesquisa. Diante dessa dificuldade, não foi possível verificar nessa pesquisa a variação das respostas de acordo com a classe social, isto é, se há variação dependendo da aplicação na escola pública ou privada. As respostas foram, majoritariamente, de escolas públicas. Os alunos matriculados no Instituto Federal Goiano - Campus Urutaí são, majoritariamente, oriundos das escolas públicas da região.

Primeiramente, um questionário foi aplicado em alunos que estavam concluindo o Ensino Médio em 2017 em duas escolas da região. 62 alunos responderam. A esses alunos de terceiros anos do Ensino Médio foi questionado: "Você sabia que o IF Goiano - Campus Urutaí oferece Ensino Médio?". 53 alunos responderam afirmativamente (85,48\%), contra 9 alunos que responderam negativamente $(14,51 \%)$. Interessante que, antes disso, foi questionado aos alunos se eles moravam na zona urbana ou na zona rural, e o resultado foi: 53 alunos moram na região urbana (85,48\%) e 9 na zona rural $(14,51 \%)$. Portanto, percebeu-se que os alunos que moram na zona rural de Pires do Rio responderam que não sabiam que o IF Goiano - Campus Urutaí oferece cursos a nível médio.

Em seguida, o questionário perguntava: "Você sabia que o IF Goiano - Campus Urutaí oferece bolsas de estudo para alunos dos cursos técnicos?". Apenas 29 alunos responderam positivamente $(46,77 \%)$, contra 33 que responderam o contrário (53,22\%). Ou seja, mesmo havendo uma maciça divulgação do instituto (diferente há quatro anos, mas não inexistente), a maioria $(53,22 \%)$ dos alunos consultados desconheciam as possibilidades de bolsas e assistência estudantil. Isso nos faz questionar sobre quantos alunos já deixaram de se matricular no Instituto Federal Goiano - Campus Urutaí por considerarem que não teriam condições de arcar com determinados custos - como o transporte, que teriam decidido pela matrícula caso tivessem essas informações. Não tem como saber como foi feita a divulgação há quatro anos.

Então, foi perguntado a esses alunos o motivo de terem estudado em outra escola ao invés de tentarem o processo seletivo para ingressarem no Ensino Médio do Instituto Federal Goiano - Campus Urutaí. O formulário continha 9 respostas:
A - Porque é longe
B - Porque não tem interesse em curso técnico
$\mathrm{C}$ - Porque costuma ter muita greve
D - Porque acho o ensino é ruim
E - Porque ouviu dizer que é muito difícil 
$F$ - Porque é ensino integral

$\mathrm{G}$ - Porque não posso pagar o transporte

H - Porque não gosto do horário de aula

I - Outro motivo

Sobre essa pergunta, primeiramente chamou a atenção o fato de que ninguém marcou a opção "porque acho o ensino ruim", enquanto que 11 alunos marcaram que "ouviram dizer que é muito difícil" (17,74\%). Logo, está no imaginário coletivo que o ensino no Instituto Federal Goiano - Campus Urutaí é de qualidade e, possivelmente, por isso mesmo, assuste alguns possíveis candidatos, com medo de fracassarem se lá ingressarem. É preciso divulgar que há uma preocupação em acompanhar o aluno, ajudando-o em suas dificuldades, por meio de cursos de nivelamento, acompanhamento de monitores, atendimento de professores e recuperação paralela.

As três respostas que mais tiveram opções marcadas (os alunos marcaram mais de uma resposta) foram: 33 alunos não estudaram no IF supostamente por ter muita greve; 25 porque é ensino integral e 22 porque não podiam pagar o transporte que, se somarmos aos 21 que responderam que o motivo é a distância, teremos então a localização rural do campus como principal fator de dificuldade. Isto é, $69,35 \%$ das respostas dos alunos concluindo o Ensino Médio em 2017 em outra escola indicaram que eles não estudaram no IF Urutaí por causa da distância do campus até a cidade.

Por fim, a última pergunta questionava se a qualidade de ensino oferecido pelo Instituto Federal Goiano era, na opinião do aluno, melhor, igual ou pior que a qualidade do ensino oferecido na escola onde ele estava. 46 alunos responderam que o ensino do IF era de melhor qualidade, enquanto que 14 alunos disseram que era igual e apenas 2 alunos disseram que era inferior. Logo, 96,77\% dos alunos aprovam o ensino oferecido no IF Goiano ou têm uma imagem positiva. Portanto, não deixaram de estudar no IF supostamente pensarem ser um ensino de má qualidade.

Também questionamos sobre a opinião dos alunos a respeito da qualidade dos professores do IF Goiano. A resposta dava três opções: se eram ótimos professores, professores comuns ou professores ruins. 43 alunos responderam que eram ótimos professores, contra 18 que responderam que eram professores comuns e 1 professor respondeu que era professores ruins. Ou seja, um resultado próximo da pergunta anterior, $98,38 \%$, o que reforça a premissa da visibilidade positiva do instituto.

A pesquisa também foi em escolas de ensino fundamental perguntar para os alunos dos nonos anos se eles teriam interesse em fazer um curso técnico no Instituto Federal Goiano. Foram questionados 140 alunos do município de Pires do Rio, sendo que 15 moravam em zona rural $(10,71 \%)$ e 125 na região urbana $(89,28 \%)$. Houve uma dificuldade de realizar a pesquisa em escolas que oferecem tanto o Ensino Fundamental quanto o Ensino 
Médio, pois nessas não foi permitido pela direção. Isso reforça a hipótese de que falamos no início da concorrência que existe entre as instituições. Então, nas escolas onde é oferecido exclusivamente o Ensino Fundamental, questionamos os alunos onde eles pretendiam estudar o Ensino Médio. 70 alunos responderam que pretendiam continuar estudando na mesma cidade e 5 responderam que iriam para Goiânia. Somente 55 disseram que pretendiam estudar no IF. Portanto, mesmo após a divulgação feita pela comissão, somente $39 \%$ dos alunos pesquisados demonstraram interesse em fazerem o processo seletivo para um curso técnico.

Também perguntamos qual a imagem que esses alunos do Ensino Fundamental têm do Instituto Federal Goiano. 100 alunos responderam que o ensino é de ótima qualidade, 35 responderam que é bom, 4 alunos respondeu que é regular e 1 aluno respondeu que é péssima. Portanto, $96 \%$ dos alunos responderam entre bom ou ótimo. Quantidade próxima da resposta sobre a qualidade dos professores, em que $89 \%$ dos alunos responderam que eles eram ótimos (125 respostas) contra apenas 15 alunos que responderam que eram professores comuns. Ninguém respondeu que eram professores ruins. Isso deixa evidente que a decisão entre estudar ou não no IF não passa pela qualidade do ensino oferecido. Ou seja, apesar de $96 \%$ ter respondido que é ótimo ou bom, somente 39\% respondeu ter interesse em estudar no IF. Por que isso acontece?

Em busca da resposta para esse questionamento, foi questionado também o motivo que levaria o aluno a estudar no IF. 65 alunos responderam que seria para ter um bom preparo para o ENEM. 50 alunos responderam que seria para ter aula com ótimos professores. Apenas $15 \%$ respondeu que seria para ter uma formação técnica. Dessa forma, é urgente informar, na divulgação, que o ensino oferecido no campus Urutaí também prepara o aluno para o ENEM, ainda que não seja seu objetivo principal. Também, em seguida, foi questionado sobre como o aluno imaginava que seria estudar no IF. 125 responderam que seria muito difícil passar de ano $(89,28 \%) .15$ alunos responderam que seria como qualquer outra escola (10,71\%). A última questão perguntava: "Se você for estudar no IF, como você vai?". 130 alunos responderam que seria de ônibus (92,85\%). 3 alunos responderam que seria com os pais. 2 alunos responderam que seria de carona. Isso deixa claro que é importante divulgar o auxílio-transporte.

\section{CONSIDERAÇÕES FINAIS}

A pesquisa feita com os alunos, tanto com aqueles que já estão cursando o Ensino Médio em outra escola, como com aqueles que estavam concluindo o Ensino Fundamental, deixou claro que, para a esmagadora maioria, os alunos não têm dúvida quanto à qualidade do ensino oferecido no Instituto Federal Goiano - Campus Urutaí. Ou seja, o motivo de não 
estudarem lá não é porque, supostamente, os cursos deixariam a desejar. Pelo contrário, pode ser que isso seja até um motivo que assusta os alunos. Como ficou evidente, eles podem ter medo de não conseguirem concluir o ensino em tempo hábil. $O$ que faz, então, com que os alunos não ingressem nos cursos técnicos oferecidos pelo IF? No caso, os dois fatores primordiais foram a distância e o desinteresse de fazer um curso técnico, já que a maioria demonstra interesse em se preparar para o ENEM na própria cidade para futuramente ingressarem em um curso superior. Isso mostra que, numa divulgação eficaz, é preciso tirar um suposto "medo" do aluno que se sente despreparado e, ao mesmo tempo, mostrar que o Ensino Médio cursado no IF Goiano deixa o aluno preparado para o ENEM e, também, focar no auxílio transporte como alternativa para superar o problema da distância.

Nos últimos anos houve uma considerável expansão dos institutos federais de educação, ciência e tecnologia que, infelizmente, não foi acompanhada de uma mudança cultural de mentalidade em que o ensino superior ainda é mais valorizado que a formação técnica. Em outras palavras, mesmo tendo cursos técnicos oferecidos próximo de casa, a maioria dos alunos ainda têm interesse em se preparar para ingressarem em uma carreira universitária. Isso, sem dúvida, dificulta o interesse dos alunos em ingressarem em uma instituição que oferece formação profissional e técnica .

Então, diante dos resultados obtidos, a divulgação está atingindo o seu objetivo? Em parte, parece que não. $O$ que se nota é que a divulgação tem sido feita no sentido de mostrar ou lembrar a existência do Instituto Federal Goiano na região próxima do município de Urutaí. Mas, se considerarmos a boa imagem que a instituição tem junto à comunidade, não é tão necessário usar mídias que divulgam a existência mas, antes, divulgar o que essa instituição pode oferecer. $46 \%$ dos alunos que fizeram o Ensino Médio em outras instituições, por exemplo, não sabiam que o IF Goiano Campus Urutaí oferecia bolsas de estudo. E, ao mostrar o que a instituição pode oferecer, ao invés de fazer uma lista para convencer o aluno pela quantidade de oportunidades, o que poderá fazê-lo se perder com tantas informações (e acabar esquecendo), focar principalmente em mostrar que o IF oferece aquilo que é do seu principal interesse: mostrar que o aluno egresso sairá de lá preparado para o ENEM, será acompanhado no percurso e terá o problema da distância superado.

Em outras palavras, os processos seletivos serão mais eficazes se demonstrarem o que o Instituto Federal Goiano oferece para o aluno, inclusive oferecendo alternativas para os medos e inseguranças que eles demonstram. Como a maioria desinteressa de estudar no IF por causa da distância, é preciso deixar claro no momento da divulgação as ações oferecidas pela assistência estudantil, principalmente o auxílio-transporte.

Se houver uma valorização da profissionalização técnica, se mostrar que o Instituto Federal Goiano pode oferecer um bom preparo para o ENEM e se demonstrar os benefícios da assistência estudantil e das bolsas 
institucionais, é muito provável que a procura de alunos no processo seletivo aumente.

Como dissemos acima, a comissão do processo seletivo de 2017 inovou ao levar membros da assistência estudantil junto em visitas às escolas para explicar esses benefícios aos alunos. Porém, como nem todas as escolas permitem essa visita, é preciso divulgar essas informações pelas mídias. Isto é, ao invés de, por meio de outdoors, rádios e folders, informar exclusivamente quais os cursos oferecidos, é preciso informar também os benefícios que ajudarão o aluno a superar os problemas que ele teme, principalmente as dificuldades de ordem financeira.

O que é veiculado pelas redes sociais e propagado individualmente ao longo do ano tem um impacto muito maior do que a campanha que é feita nas rádios e nos outdoors no momento do processo seletivo. Ou seja, é importantíssimo que, durante todo o ano, seja divulgada pelas redes sociais, o preparado para o ENEM, o auxílio-transporte e a ajuda aos alunos com dificuldade de aprendizagem.

Outro ponto importante é que a página do Facebook do IF Goiano Campus Urutaí é curtida principalmente por quem já é aluno da instituição. Nesse sentido, é preciso que essa página seja divulgada para os alunos do Ensino Fundamental que são alunos em potencial. Assim, além de incrementar a divulgação por meio da página oficial, também é preciso verificar constantemente o que está sendo veiculado e tentar neutralizar possíveis mensagens negativas por meio de divulgações positivas.

Por falta de tempo não foi possível verificar se os alunos tiveram contato com as mídias divulgadas. Não se analisou a recepção das mídias, mas a sua percepção. Ou seja, não foi possível verificar se as mídias que estavam sendo veiculadas alteraram a percepção dos adolescentes. Diante da discussão teórica que foi feita no início, pressupõe-se que as respostas foram feitas com base na imagem que eles já tinham de antemão. Por ser tratar de uma pesquisa de iniciação científica, também tivemos dificuldade para um levantamento de dados mais amplo, que não impede que seja contemplado em pesquisas posteriores. Isto é, perceber as mudanças analisando sucessivas divulgações e processos seletivos anuais. Isso não invalidou os resultados se pensarmos que o principal problema é que os adolescentes não sabem do que o Instituto Federal oferece. Além disso, nosso objetivo nessa pesquisa foi compartilhar resultados, informações e procedimentos metodológicos também para futuras pesquisas feitas por outras instituições. De forma que, futuramente, será possível comparar essas informações com as informações de outras instituições.

Como dissemos acima, quem escolhe a escola para se estudar o Ensino Médio? Geralmente os próprios adolescentes, e um dos principais fatores que afetam a escolha, é acompanhar os amigos do Ensino Fundamental. Quando chegam a um novo ambiente, desconhecido e 
desafiador é a companhia já conhecida do colega da escola anterior que lhe proporciona meios para uma nova socialização. A palavra final, na maioria das vezes, será dos pais, se sim ou se não, mas a iniciativa será do adolescente.

É, portanto, muito importante que toda estratégia de marketing seja feita visando atingir, primeiramente o adolescente, para despertar nele $O$ desejo de estudar em uma instituição de ensino profissionalizando. Nesse sentido, usar as redes sociais de forma constante será o meio mais eficaz. E, em segundo lugar, criar uma imagem positiva para que os pais concordem. Diante do que foi exposto, não seria o caso de trocar as mídias usadas, mas de acrescentar outras estratégias. Para isso, pode-se usar, como apoio, outras mídias, como divulgação em rádios nos períodos mais próximos dos processos seletivos.

Em síntese, diante do que foi exposto, é recomendável: 1. Fazer uma campanha midiática constante por meio de redes sociais tendo, individualmente, o adolescente do ensino fundamental como público-alvo; 2. Essa campanha poderá privilegiar a divulgação das alternativas oferecidas para os alunos em dificuldades (monitorias, cursos, atendimento fora de sala), os auxílios oferecidos que superem a distância do campus e o preparo do ensino para o ENEM e 3. No final do ano, uma campanha específica em meios de comunicação de massa tendo como público-alvo os pais desses adolescentes.

\section{REFERÊNCIAS}

CARDOSO, R. L.; ROCHA, C. M. F. A relação do público jovem com o rádio na atualidade. São Paulo: Revista Comunicação, mídia e consumo. Vol. 8. N. 22, 2011.

CUNHA, L. A. Ensino Médio e ensino técnico na América Latina: Brasil, Argentina e Chile, 2000.

MAIA, A. RIBEIRO, R. YOSHIMURA, T. Outdoor da pós-graduação Uni Anhanguera. Intercom - Sociedade Brasileira de Estudos Interdisciplinares da Comunicação XXIII Prêmio Expocom 2016 - Exposição da Pesquisa Experimental em Comunicação.

MOLINERO, B. Adolescentes devem ser ouvidos sobre troca de escola, mas adultos decidem. Jornal Folha de São Paulo. São Paulo, 10 de setembro de 2017.

SCHEID, D. Estratégias e lógicas envolvidas na construção da visibilidade institucional em diferentes espaços de interação na internet. Santa Maria: Universidade Federal de Santa Maria. Dissertação de mestrado. 2008. 
SILVA, J. C.; BARBOSA, F. M. T. Estrada de ferro, Goiás e a modernização do território goiano: o caso de Pires do Rio. Iporá: Revista Sapiência, 2017. 